\title{
Kinetic and deactivation differences among methanol, dimethyl ether and chloromethane as stock for hydrocarbons
}

\author{
José Valecillos ${ }^{[a]}$, Hegoi Manzano ${ }^{[b]}$, Andrés Aguayo ${ }^{[a]}$, Javier Bilbao ${ }^{[a]}$, Pedro Castaño*[a,c]
}

\begin{abstract}
The conversions into hydrocarbons of methanol, dimethyl ether and chloromethane (MTH, DTH and CTH, respectively) on a H-ZSM- 5 zeolite catalyst were compared trough ab-initio calculations and experiments, using a fixed-bed reactor and in-situ FTIR spectroscopy. The molecular modelling of the reaction was performed using force field calculations. The nature and location of retained species were assessed by a combination of techniques. The experimental results of activity, product distribution and deactivation match these of the molecular modelling as the three reactions proceed through the dual-cycle mechanism. However, the initiation, evolution and degradation of hydrocarbon pool species are kinetically different depending on the reactant. The reactions are faster in the order DTH > MTH >> CTH whereas the rate at which coke forms and grows (linked with the rate of deactivation) is in the order $\mathrm{CTH}>>$ DTH $>$ MTH.
\end{abstract}

\section{Introduction}

The forecasted decrease of availability of crude oils justify the increase of industrial implementations for less conventional fossil resources such as carbon or natural gas. ${ }^{[1]}$ Aiming the circular economy and the cut of greenhouse gases, new processes are being developed for incorporating renewable (solar or biomass) and waste feeds as source of fuels and chemicals. ${ }^{[2-4]}$ In this scenario, the production of hydrocarbons, particularly the most demanded light olefins, from alternative sources out of crude oils is attracting a great attention from industry and academia. ${ }^{[5]}$

There are several routes to produce light olefins in a sustainable manner, the ones represented in Figure 1 are attractive as for its application at industrial scale and to substitute the routes based on crude oil. ${ }^{[6,7]}$ These routes use methanol, dimethyl ether (DME) or chloromethane as intermediates, a zeolite or zeotype catalyst and besides light olefins, their selectivity can be redirected towards gasoline with enhanced $\mathrm{C}_{5+}$ aliphatic

[a] J. Valecillos, Prof. A.T. Aguayo, Prof. J. Bilbao, Dr. P. Castano Department of Chemical Engineering

University of the Basque Country (UPV/EHU)

P.O. Box 644, 48080. Bilbao, Spain.

E-mail: pedro.castano@ehu.eus

[b] Dr. H. Manzano

Department of Condensed Matter Physics

University of the Basque Country (UPV/EHU)

P.O. Box 644, 48080. Bilbao, Spain.

[c] Dr. P. Castano

Multiscale Reaction Engineering, KAUST Catalysis Center (KCC)

King Abdullah University of Science and Technology (KAUST)

Thuwal, 23955-6900, Saudi Arabia.

E-mail: pedro.castano@kaust.edu.sa composition or aromatics, in general, hydrocarbons. Methanol and DME can be obtained from reforming or gasification of natural gas, carbon, biomass or plastic waste, and the subsequent synthesis step. In fact, this last step can be used to incorporate $\mathrm{CO}_{2}$ into the cycle. ${ }^{[8,9]}$ On the other hand, the chloromethane can be obtained in one step from natural gas by oxychlorination. ${ }^{[10]}$ Among the three individual and final routes (on zeolite or zeotype catalyst), that of methanol to hydrocarbons (MTH) has attracted the greater interest and has been scale-up in China, ${ }^{[11]}$ while the other two routes (DME and chloromethane to hydrocarbons, DTH and CTH respectively) are under study. ${ }^{[12-16]}$

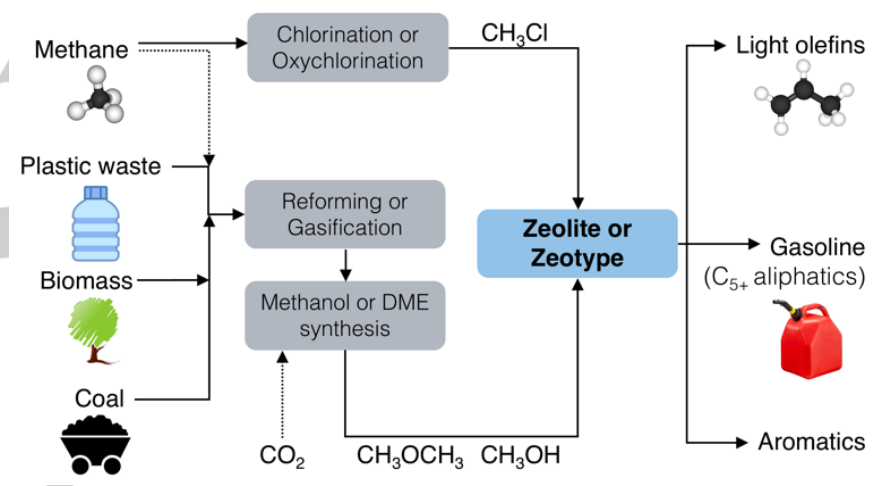

Figure 1. Alternative and competing routes for producing light olefins, gasoline and aromatics from different renewable, waste and fossil resources.

An overview of the extensive literature on MTH, DTH and CTH reactions indicate that (i) the most studied catalysts are H-ZSM5 zeolite and SAPO-34 zeotype, whereas (ii) the mechanisms of reaction are essentially similar. Normally, H-ZSM-5 zeolite catalyst is recognized by its high selectivity to $\mathrm{C}_{5_{+}}$aliphatics or aromatics, relatively high selectivity of light olefins and extended lifetime, which can be extended even further with promoters. ${ }^{[17]}$ On the other side, SAPO-34 zeotype catalyst is well-known for its extremely high light olefin selectivity and much shorter lifetime. ${ }^{[18]}$ Regardless the reaction, the mechanisms of reaction implicate the dual-cycle of olefins and aromatics with parallel reactions such as hydrogen transfer and condensation. ${ }^{[19-23]}$ According to this mechanism, each reactant (methanol, dimethyl ether or chloromethane) is transformed into a pool of organic intermediates, that lead to different hydrocarbons: light olefins at short space times, while paraffins and aromatics at longer space times. Active hydrocarbon pool (HCP) species include olefins, poly-methyl benzenes and poly-methyl cyclopentenyl cations. ${ }^{\text {[24- }}$ ${ }^{26]}$ Besides the "straight" reactions that these species suffer in the vicinity of acid sites -such as methylation, dealkylation, hydrogen transfer, cyclization and oligomerization, among others-, additional degradation reactions occur in order to form 
less active or even deactivating species such as poly-methyl napthalenes and ultimately coke. ${ }^{[27,28]}$ Thus, the sequenced individual steps ${ }^{[29,30]}$ of these reactions are (i) dissociation and methoxy species formation; (ii) initial C-C formation; (iii) formation of HCP species; (iv) methylation and scission to release light olefins; $(v)$ secondary reactions of light olefins such as hydrogen transfer or condensation; and (vi) secondary reaction of HCP species to form coke.

The early $\mathrm{C}-\mathrm{C}$ bond formation in step (ii) has been a mayor research drive in the last years, ${ }^{[31,32]}$ together with the comparison of methanol vs. dimethyl ether, which has been recurrently studied in the literature. Forester and Hower ${ }^{[33]}$ indicated that DTH reaction required less activation energy to proceed as compared with MTH. Martinez-Espin et al. ${ }^{[34]}$ have compared DTH vs. MTH a variety of catalyst (including $\mathrm{H}-\mathrm{ZSM}-5$ zeolite) concluding that the former has the following benefits compared with the latter: higher activity, lower yield of aromatics and ethylene (normally regarded as a secondary interest product) and slower deactivation. The same group ${ }^{[35,36]}$ has pointed to the fact that DTH is faster than MTH is due to the faster and thermodynamically favored methylation over hydrogen transfer reactions (in principle unwanted). Li et al. ${ }^{[37]}$ proved similar behavior when SAPO-34 catalyst is used. PérezUriarte et al. determined that the kinetic constant of light olefins formation is greater for DME than for methanol ${ }^{[38]}$ and that of deactivation is greater too. ${ }^{[39]} \mathrm{Xu}$ et al. ${ }^{[40]}$ and Fickel et al. ${ }^{[16]}$ ratified that chloromethane suffer a similar sequence of transformations than methanol or DME, while Gamero et al. ${ }^{[15]}$ have identified that the entire reaction network of chloromethane is similar than the oxygenate counterparts. However, the observed reactivity of chloromethane is slower due the thermodynamically harder formation of methoxy species from this reactant. ${ }^{[41,42]}$ Other significant difference of CTH is the inexistence of water in the reaction medium, which is regarded as one key factor governing the faster deactivation rate of this reaction as compared with $\mathrm{MTH}$ and DTH. ${ }^{[43]}$

This work compares the thee sources of hydrocarbons (MTH, DTH and CTH reactions) on the grounds of product distribution, kinetic and deactivation performances. These results have been obtained experimentally in a fixed-bed or in an operando (in-situ FTIR) reactor. At this level, the basis of the comparison has been using exactly the same reaction conditions, in terms of space time or time on stream, and aunique H-ZSM-5 zeolite catalyst. Then, the experimental observations were compared with the theory by molecular modelling simulations of some key kinetic steps of the reactions. Although. all three reactionsproceed through the same pathways, we expect that certain kinetic and deactivation differences would have a major impact on the final choice of the source of hydrocarbons.

\section{Results}

\section{Fixed-bed reactor runs}

Figure $2 \mathrm{a}$ shows the evolution of DTH, MTH and CTH conversion for different space times values (in logarithmic scale to facilitate the comparison), normalized as the number of Brønsted acid sites ( $n_{\text {BAS }}$ ) per flowrate of reactant in $\mathrm{C}$ or $\mathrm{CH}_{3}$ basis: $n_{B A S} / F_{\text {in }} \mu$ mol $_{B A S} h$ mol $_{\mathrm{CH}{ }^{-1}}$. Note that dimethylether has two $\mathrm{C}$ or $\mathrm{CH}_{3}$ units per one of methanol. These results have been taken after $20 \mathrm{~min}$ on stream. The conversion profiles of the three reactants can be fitted to a first reaction order kinetics with an autocatalytic or initiation period, making a sigmoidal behavior. Figure $2 \mathrm{a}$ shows that the rates of MTH and DTH conversions are relatively similar with a slightly slower initiation period for the former. On the other side, CTH rates of conversion and initiation are significantly slower these of the oxygenated counterparts. This observation is an important kinetic indicator suggesting that chloromethane requires a higher space time in order to achieve a similar conversion level comparable to that of methanol or dimethyl ether. Dimethyl ether has the fastest kinetics with the same concentration of $\mathrm{CH}_{3}$ groups in the reaction medium, as it exhibits relatively higher conversions than methanol. Figure $2 \mathrm{~b}$ shows the deactivation profiles, using the same space times $\left(\mathrm{n}_{\mathrm{BAS}} / \mathrm{F}=196.3 \mu \mathrm{mol}_{\mathrm{BAS}} \mathrm{h} \mathrm{mol} \mathrm{CH}^{-1}\right)$ and different values of time on stream (TOS). DTH and MTH reactions show high and stable levels of conversion during 240 min on stream whereas CTH reaction shows lower levels of conversion reaching a maximum at $35 \mathrm{~min}$. It is clear that DTH and $\mathrm{MTH}$ reactions take place with an excess of catalyst as long as CTH reaction is limited by the catalyst amount which is not the best choice to compare catalytic performance. ${ }^{[44,45]}$ When we analyze the behaviors of the reaction with $n_{B A S} / F$ and TOS, we observe a significant conversion drop for the $\mathrm{CTH}$ reaction. In the first $20 \mathrm{~min}$ on stream, the conversion increases up to $65 \%$ indicating a slower initiation period and afterward it progressively decreases down to $46 \%$ at $240 \mathrm{~min}$ on stream indicating that the catalyst deactivation is faster. Thus, the presence of a halide in the structure of the reactant causes: (1) a slow-down of the conversion of $\mathrm{CH}_{3}$ groups into hydrocarbons regardless of the fact that there is the same number of active sites per mole of $\mathrm{CH}_{3}$ groups fed; and (2) an acceleration of the catalyst deactivation. The factor (1) is due to the slower adsorption of chloromethane ${ }^{[46]}$ and its subsequent scission, ${ }^{[42]}$ compared with these of methanol or dimethyl ether. The two main players behind deactivation are coke deposition and dealumination of the zeolite due to the presence of $\mathrm{H}_{2} \mathrm{O}$ or $\mathrm{HCl}$ in the reaction medium. The reaction temperature employed in this work $\left(400{ }^{\circ} \mathrm{C}\right)$ enable to exclude the dealumination pathway for all reactions, and point to coke as the main cause of catalyst deactivation, as previously determined. ${ }^{[43,47,48]}$ Based on the fact that the main cause of deactivation is coke formation, then the results of Figure 2a suggest that chloromethane is more prone to form coke, which should be verified later.

In all of the experiments we observed the formation of a wide variety of hydrocarbons in the gas-vapor phase as previously reported. These hydrocarbons are similar in nature for the three reactions and they mainly consist of methane, $\mathrm{C}_{2}-\mathrm{C}_{4}$ olefins, $\mathrm{C}_{2-}$ $\mathrm{C}_{4}$ paraffins, $\mathrm{C}_{5+}$ aliphatics and aromatics. However, one relevant difference is the formation of water as a secondary 
product in the MTH and DTH reactions (particularly in the former) in contrast to the formation of $\mathrm{HCl}$ in the $\mathrm{CTH}$ reaction. We focus on the formation of $\mathrm{C}_{2}-\mathrm{C}_{4}$ olefins from each feedstock as a key product, which is an intermediate in the whole reaction network. ${ }^{[15,38]}$ Figure $2 c$ represents the yield olefins $\left(Y_{\text {olefins }}\right)$ as a function of the conversion of each reactant using different values of space time at a unique TOS $=20 \mathrm{~min}$. Interestingly, the $\mathrm{Y}_{\text {olefins }}$ profile is unique for MTH and DTH reactions and thus, the reactivity of the reaction media (not only the reactant) is similar among the two reactions. CTH reaction shows a different $Y_{\text {olefins }}$ profile along the conversion compared to that of MTH and DTH reactions: higher at intermediate conversions (up to $75 \%$ ) and smaller at high conversions $(75-100 \%)$. In other words, the highest selectivity of olefins is obtained with intermediate conversions in the CTH reaction. Figure $2 d$ shows the $Y_{\text {olefins }}$ as a function of the conversion of each reactant using different TOS and the same space time $\left(\mathrm{n}_{\mathrm{BAS}} / \mathrm{F}=196.3 \mu \mathrm{mol}_{\mathrm{BAS}} \mathrm{h} \mathrm{mol}_{\mathrm{CH}}{ }^{-1}\right)$. The lines represent the same ones represented in Figure 2c. For MTH and DTH reactions the product yield in is predominantly independent on the deactivation and the coke content. ${ }^{[49]}$ However, this is not the case for CTH reaction. Note that the line connects $Y_{\text {olefins }}$ and conversion and TOS $=20 \mathrm{~min}$. In the initiation period of $\mathrm{CTH}$ reaction, the $Y_{\text {olefins }}$ is greater that the predicted for the conversion degree, however this value drops as the catalyst deactivates and reaches the trend of MTH and DTH reactions.
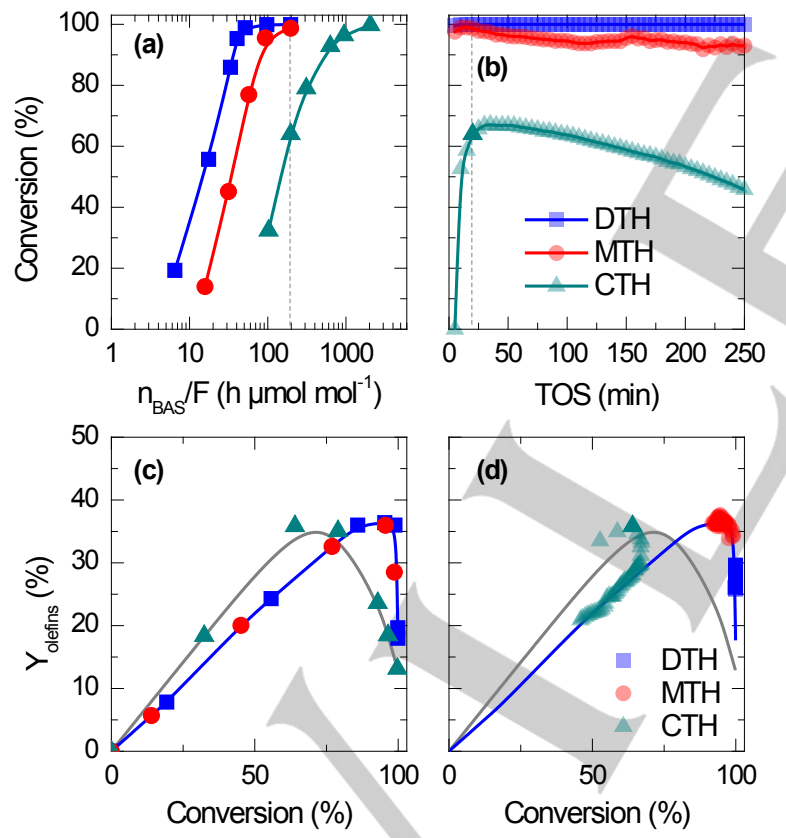

Figure 2. Kinetic behavior for the MTH, DTH and CTH reactions: (a) evolution of conversion as a function of the space time referred to the number of Brønsted acid sites at TOS $=20 \mathrm{~min}$; (b) evolution of conversion as a function of the time on stream at $n_{B A S} / F=196.3 \mu$ mol $_{B A S} h$ mol $_{\mathrm{CH}_{3}}{ }^{-1}$; (c) yield of light olefins as a function of conversion at different space times at TOS $=20 \mathrm{~min}$; and (d) yield of light olefins as a function of conversion at different time on streams at $\mathrm{n}_{\mathrm{BAS}} / \mathrm{F}=196.3 \mu$ molBAS $_{\mathrm{B}} \mathrm{mol}_{\mathrm{CH}}{ }^{-1}$. Lines represent the trends obtained in (c). Reaction conditions: $400^{\circ} \mathrm{C}$ and $1.5 \mathrm{~atm}$.
To summarize the results presented in Figure 2, DTH and MTH reactions are relatively similar in terms of the evolution of product distribution with the conversion decay (deactivation). DTH shows faster initiation and conversion steps than MTH. On the other hand, CTH reaction presents significantly slower initiation and conversion steps, while having faster deactivation. All these drawbacks become an advantage for controlling the selectivity of intermediates such as olefins. Thus, the selectivity of these species can be enhanced.

We analyze in detail the product distribution in gas-vapor phase and retained species with minor contribution of the deactivation, which occurs at $20 \mathrm{~min}$ on stream (conditioned by the CTH reaction). For quantifying the product distribution and the retained species for the three reactions in a simplified manner, the compositions of these two mediums have been plotted vs. carbon number and classified in terms of the double bond equivalent (DBE). This plot corresponds to Figure 3, arranged with the product distribution on the left side, and the corresponding retained species on the right side. DBE represents the degree of instaurations of a particular component, and it is practical for quantifying the analysis of hydrocarbon mixtures. ${ }^{[50]}$ It is determined as:

$\mathrm{DBE}=\mathrm{C}+1-\mathrm{H} / 2$

where $\mathrm{C}$ and $\mathrm{H}$ are the number of carbons and hydrogen of each molecule, respectively. Therefore, species with $\mathrm{DBE}=0$ can be regarded as methane (carbon number $=1$ ) or paraffins; $\mathrm{DBE}=2$, olefins (naphthenes are virtually undetected); $\mathrm{DBE}=4$, 1-ring aromatics; $\mathrm{DBE}=6$, 2-ring aromatics.

In the product distribution at $20 \mathrm{~min}$ on stream and regardless the reactant used, the $\mathrm{C}_{5+}$ aliphatic lump (aliphatic gasoline fraction) is mainly constituted by olefins and it has been represented as $\mathrm{DBE}=1$, since only traces of paraffins $(\mathrm{DBE}=0)$ could be detected. The selectivity of methane is significantly higher for the CTH compared with that of MTH or DTH, which is attributed to the direct decomposition of chloromethane, ${ }^{[51]}$ which also is indicative of catalyst deactivation. The yield of light olefins follows the trend $\mathrm{CTH}>\mathrm{MTH} \approx \mathrm{DTH}$, whereas its distribution (within number of carbons) is relatively different: CTH has a narrow distribution, highly olefinic, centered in $\mathrm{C}_{4}$ hydrocarbons, whereas MTH and DTH have a broader distribution. The yield of secondary products as $\mathrm{C}_{5+}$ aliphatics, paraffins and aromatics is much higher for DTH and MTH, whereas its distribution is relatively similar for those, compared with that of $\mathrm{CTH}$. These secondary products are formed through reactions of light olefins such as hydrogen transfer and oligomerization, which are favored at higher levels of conversion with an excess of catalyst. 

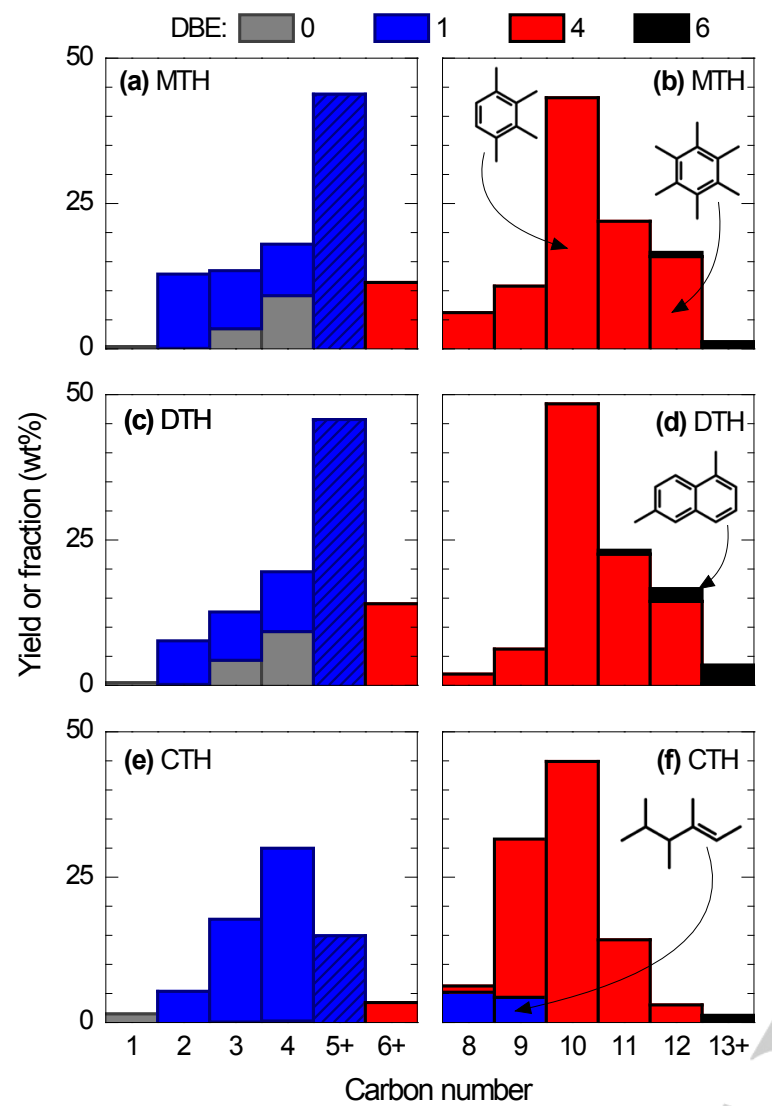

Figure 3. Distribution of products (a, c and e) and retained HCP species (b, d and f) at $20 \mathrm{~min}$ on stream for the MTH, DTH and CTH reactions. Note that the $\mathrm{C}_{5+}$ aliphatic lump (aliphatic gasoline fraction) is constituted by olefins (DBE = 1 ), and traces of paraffins (DBE $=0$ ) and that is why it has been represented with stripes. Reaction conditions: $400{ }^{\circ} \mathrm{C} ; 1.5 \mathrm{~atm}$; $\mathrm{n}_{\mathrm{BAS}} / \mathrm{F}=196.3 \mu$ mol$_{\mathrm{BAS}} \mathrm{h}$ $\mathrm{mol}_{\mathrm{CH} 3}{ }^{-1}, 20 \mathrm{~min}$ on stream.

Figure 3 also shows the distribution of the retained HCP species extracted from the catalyst after 20 min time on stream. These species have a pivotal role as active species and as coke precursors. The distribution of HCP species for MTH and DTH reactions is centered at tetramethyl benzenes (carbon number $=$ 10) with a high contribution of pentamethyl benzenes (11) and hexamethyl benzenes (12). At the same time, the catalyst has a significant amount of dimethyl and trimethyl naphthalenes (DBE $=6$ and carbon number $=12$ and 13 , respectively). Those species are known to have a lower intrinsic methylation rate than polymethyl benzenes ${ }^{[52]}$ and to be precursors for more deactivating species. ${ }^{[53]}$ For $\mathrm{CTH}$ reaction the distribution of HCP species is also centered at tetramethyl benzenes, but the proportion of bulkier methylated benzenes and naphtalenes is neglected by the increase of the proportion of trimethyl benzenes and olefins (DBE $=1)$. These results indicate that the HCP species are more evolved in the case of MTH and DTH than for $\mathrm{CTH}$, and this evolution is linked with species with lower methylation activity, methylated naphthalenes in particular. ${ }^{[27]}$ Moreover, the HCP species on the DTH reaction are bulkier and less active for methylation than these on the MTH reaction. Thus, the type of reactant is important in the evolution control of HCP species, with the aim of minimizing the catalyst deactivation, as other author aimed before. ${ }^{[54,55]}$ The interesting issue is that the CTH reaction has less alkylated aromatics and more olefins, which are more "active" species than the counterparts detected in the MTH and DTH reactions. At the same time, CTH reaction has the lowest conversion $(\sim 65 \%)$ compared with the other two reactions $(\sim 100 \%)$ as observed in Figure 2 (35 min). These two observations point out to the fact that the rate of methylationdealkylation of any HCP species is slower for $\mathrm{CTH}$ reaction than for MTH and DTH reactions. However, another interesting observation is that the trend of methylated naphthalenes concentration in the HCP species is the inverse of the conversion (Figures 2 and 3). Thus, the formation of coke in the CTH reaction should be dominated by another pathway different from the evolution and degradation of the HCP species.

In order to compare the evolution of the three reactions on a mechanistic basis, two representative reaction indexes have been plotted over the conversion of each reactant in Figure 4: the selectivity ratio of propylene to ethylene $\left(S_{P} / S_{E}\right)$ in Figure $4 a$, and the selectivity ratio of ethylene to isobutane $\left(S_{E} / S_{I}\right)$ in Figure $4 \mathrm{~b}$. The lines of these figures correspond to experiments using different $n_{B A S} /$ Fat TOS $=20$ min whereas the points represent

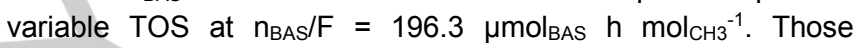
indexes previously used in the literature ${ }^{[20,23,56,57]}$ enable to study the dual cycle mechanism on the MTH reaction and compare the effect of the conversion or the co-feeding of different species. In this work, we have used the same mechanistic concepts to compare the MTH, DTH and CTH reactions. As seen in Figure 4, DTH and MTH reactions behave similarly for any given value of conversion indicating the similar reactions pathways of the two reactants. However, CTH reaction shows significant differences in the indexes are observed among the reactions. The $S_{P} / S_{E}$ index is almost 3 times higher for CTH than for MTH and DTH reactions (Figure $4 a$ ). At the same time, the values of $S_{E} / S_{\text {I }}$ follow a trend that depend on the conversion level and more importantly on the reactant used. In the case of $\mathrm{CTH}$ reaction the value of $S_{P} / S_{E}$ increase even further over TOS.
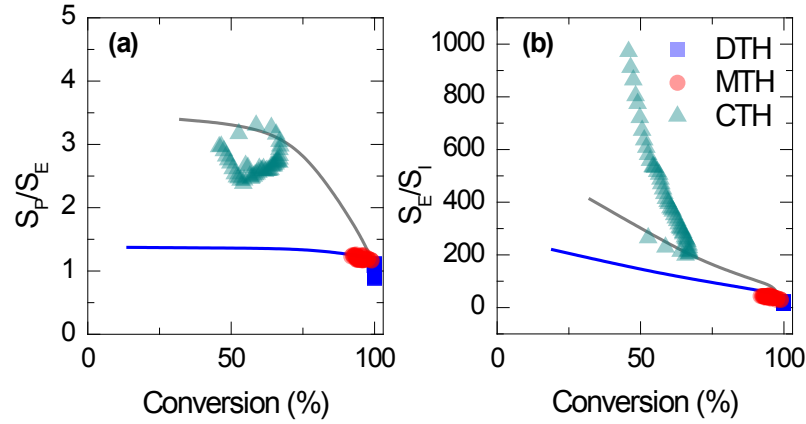

Figure 4. Evolution of reaction indexes with conversion in the MTH, DTH and CTH reactions: (a) selectivity ratio of propylene to ethylene $\left(\mathrm{S}_{\mathrm{P}} / \mathrm{S}_{\mathrm{E}}\right),(\mathrm{b})$ selectivity ratio of ethylene to isobutane $\left(\mathrm{S}_{E} / \mathrm{S}_{\mathrm{I}}\right)$. Lines represent datapoints obtained under different $\mathrm{n}_{\mathrm{BAS}} / \mathrm{F}$ whereas points represent datapoints obtained under different TOS. Reaction conditions: $400{ }^{\circ} \mathrm{C}$; $1.5 \mathrm{~atm}$. 
In light of the results shown in Figure 4b, we can affirm that despite the fact that the dual cycle mechanism is fundamentally identical for the three reactions, the CTH reaction shows faster aromatic cycle propagation at intermediate conversions (coinciding with higher yield and selectivity of light olefins, Figure 4) leading to much higher proportion of propylene over ethylene (almost 3 times). This faster propagation is detrimental at longer TOS because the catalyst deactivates faster and its light olefin selectivity drops to DTH and MTH reactions (Figure 4b)

\section{In-situ FTIR spectroscopy}

Besides the fixed bed reactor runs, we performed the reactions in an in-situ FTIR transmission cell at $400{ }^{\circ} \mathrm{C}$ by dosing pulses of each of the three reactants. Figure 5 shows the FTIR spectra in two regions (1400-1700 $\mathrm{cm}^{-1}$ and $2800-3200 \mathrm{~cm}^{-1}$ ) of the species retained in the catalyst after the same exposure of reactants (similar equivalent space time and time on stream). The FTIR bands has been ascribed to the following species:[58] $3080 \mathrm{~cm}^{-1}$, olefins; $3050 \mathrm{~cm}^{-1}$, single ring aromatics; $2980 \mathrm{~cm}^{-1}$, olefins; 2955 and $2855 \mathrm{~cm}^{-1}$, terminal aliphatic $\left(-\mathrm{CH}_{3}\right)$ groups; $2925 \mathrm{~cm}^{-1}$, linear and branched aliphatic $\left(-\mathrm{CH}_{2}\right.$ and $\left.-\mathrm{CH}\right)$ groups; $1620 \mathrm{~cm}^{-1}$, conjugated double bonds in dienes and polyaromatics (coke); $1591 \mathrm{~cm}^{-1}$, alkylated aromatics lowly condensed; $1570 \mathrm{~cm}^{-1}$, polycondensed aromatics in coke; and $1478 \mathrm{~cm}^{-1}$, alkylated aromatics. As shown in Figure 5, the in-situ FTIR is not able to distinguish significant differences in the HCP species nature (olefins, single ring aromatics and aliphatic groups in the 2800$3200 \mathrm{~cm}^{-1}$ region) among the three reactions, further that the greater intensity of those for MTH > DTH > CTH. The significant difference in the alkylation of HCP species observed in Figure 3 cannot be corroborated by the in-situ FTIR results due to the considerably lower relative vibrational band of single-ring aromatics $\left(3050 \mathrm{~cm}^{-1}\right)$ compared with the aliphatic ones (2955$2855 \mathrm{~cm}^{-1}$ ) at the same level of concentration.
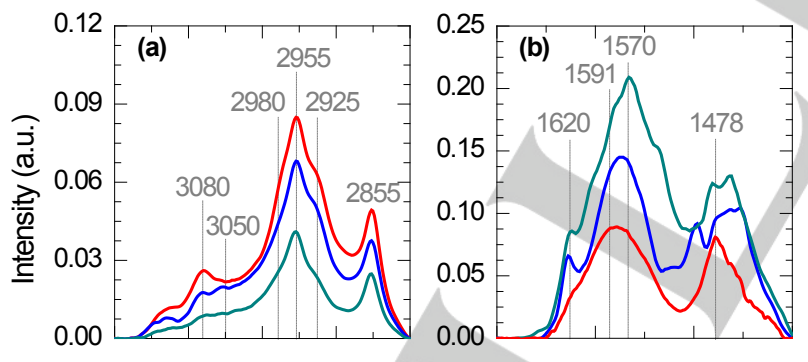

$\begin{array}{lllll}3200 & 3100 & 3000 & 2900 \quad 2800 & 1700\end{array}$

Wavenumber $\left(\mathrm{cm}^{-1}\right)$

Figure 5. FTIR spectra of catalysts exposed to similar amounts of chloromethane, dimethyl ether or methanol at $400{ }^{\circ} \mathrm{C}$ in the (a) $2800-3200 \mathrm{~cm}$ ${ }^{1}$ and (b) $1400-1700 \mathrm{~cm}^{-1}$ regions.

Figure $5 \mathrm{~b}$ shows that the bands associated with more condensed and alkylated aromatics and dienes $\left(1400-1700 \mathrm{~cm}^{-1}\right.$ region) follows the trend $\mathrm{CTH}>\mathrm{DTH}>\mathrm{MTH}$, which at the same time is inverse to the HCP species $\left(2800-3200 \mathrm{~cm}^{-1}\right.$ region). These observations lead to conclude there is a higher proportion of highly condensed coke molecules in the $\mathrm{CTH}$ reaction, which at the same time is corroborated with the fact that the main coke band is shifted from 1583 to $1571 \mathrm{~cm}^{-1}$ in the CTH reaction: the coke with a vibrational band at $1571 \mathrm{~cm}^{-1}$ is regarded as more condensed than the one at $1583 \mathrm{~cm}^{-1} .{ }^{[59]}$

\section{Nature and location of deactivating species}

Figure 6 summarizes the deterioration of the textural properties of the catalyst after DTH, MTH, and CTH reaction runs of 240 min. The extent of the deterioration (compared with the fresh catalyst) can give insights of the location of HCP species and coke. ${ }^{[13]}$ The decrease of the micropore area follows the trend $\mathrm{CTH}>\mathrm{DTH}>\mathrm{MTH}$, whereas that of the mesopores area follows the trend $\mathrm{CTH}>\mathrm{MTH}>\mathrm{DTH}$. These trends allow to rationalize that the deterioration of the catalyst and micropores in particular, is strongly correlated with the deactivation stage. This rapid deactivation could be correlated with the high content of polycondensed aromatics in coke (Figure 5b), which are deposited on the meso- and macropores of the matrix, blocking access to the acid sites in the micropores of the zeolite.

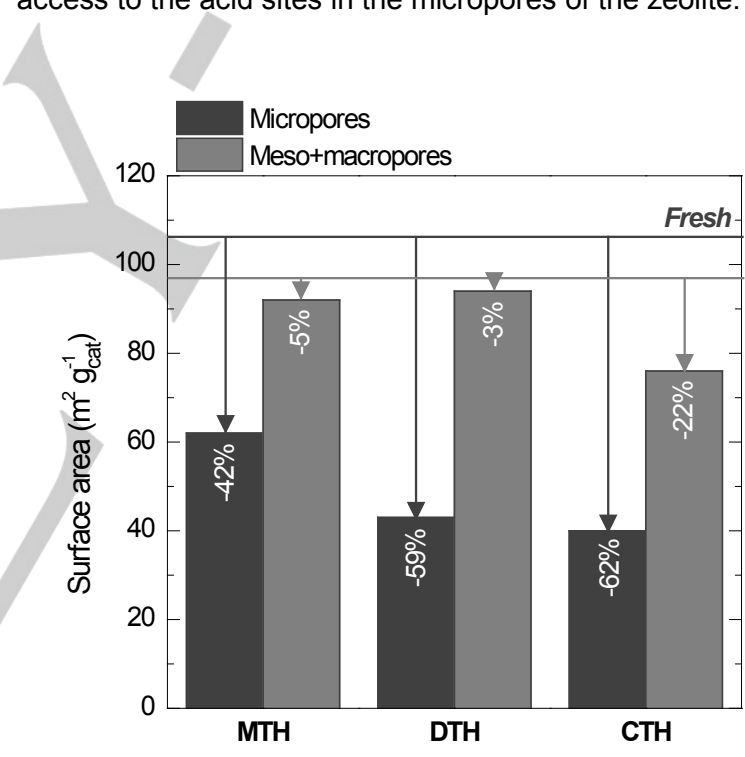

Figure 6. Deterioration of textural properties of spent catalysts after MTH DTH and CTH reactions. Reaction conditions: $400{ }^{\circ} \mathrm{C} ; 1.5 \mathrm{~atm} ; \mathrm{n}_{\mathrm{BAS}} / \mathrm{F}=196.3$ $\mu$ mol $_{\text {BAS }} \mathrm{h} \mathrm{mol} \mathrm{CH}_{3}{ }^{-1} ; 240$ min on stream.

To prove the mentioned hypothesis, the amount of HCP and coke species retained on the catalysts, and the location of coke, have been studied. Figures 7 shows the profiles of the temperature programmed desorption (TPD) using a flow of $\mathrm{N}_{2}$ and of these of temperature programmed oxidation (TPO) with air, corresponding to catalysts used in the three reactions after 35 and $240 \mathrm{~min}$, respectively. In the TPD profiles (Figures $7 \mathrm{a}$ and $8 \mathrm{a}$ ), the weight loss can be ascribed to adsorbed and retained species on the catalyst including water and coke precursors that are HCP species. ${ }^{[60]}$ The amount of these TPD species deposited on the catalysts used in the three reactions 
(Figure 7a) is similar after 20 min time on stream (2.1-2.4 wt\%) with the trend MTH > DTH > CTH, in agreement with the results presented in Figure 5a. The amount of TPD species increases with the time on stream for the DTH reaction (from 2.3 up to 2.9 wt\%, Figures $7 \mathrm{a}$ and $7 \mathrm{~b}$ ), keeps constant for the $\mathrm{CTH}$ reaction (2.1 wt\%) and slightly decreases for the MTH reaction (from 2.4 to $2.1 \mathrm{wt} \%$ ). The last observation is due to the transformation of those species into gaseous products or, more importantly, into condensed aromatic species (coke).

On the other hand, in the TPO profiles (combustion of the species remaining on the catalyst after the TPD) shown in Figures $7 c$ and $7 d$, the weight loss is directly attributed to coke species. The TPO profiles show the existence of two types of coke, which oxidize at different temperatures due to each intrinsic location or composition: coke I (burning at $420{ }^{\circ} \mathrm{C}$ ) is deposited mainly on the mesopores of the catalyst and has a more aliphatic nature; coke II (burning at $520{ }^{\circ} \mathrm{C}$ ) is primarily deposited on the micropores of the catalyst and has more aromatic nature. ${ }^{[61]}$ This differentiated location is also indicative of the respective deactivating effect: ${ }^{[62]}$ coke II (blocking the active sites) affects more to the catalyst performance than coke I (per gram deposited).

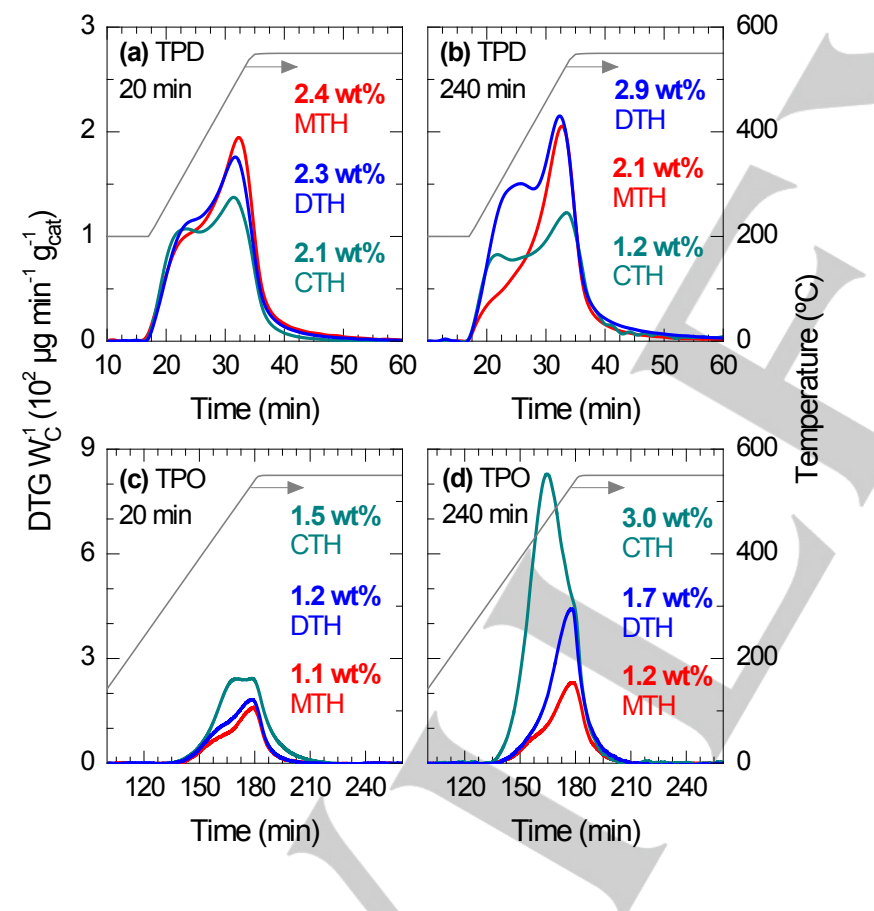

Figure 7. DTG profiles of spent catalysts after the MTH, DTH and CTH reactions: (a) TPD after $20 \mathrm{~min}$ on stream, (b) TPD after 240 min on stream, (c) TPO after 20 min on stream, (d) TPO after 240 min on stream. Reaction conditions: $400{ }^{\circ} \mathrm{C} ; 1.5 \mathrm{~atm} ; \mathrm{n}_{\mathrm{BAS}} / \mathrm{F}=196.3 \mu$ mol $_{\mathrm{BAS}} \mathrm{h} \mathrm{mol} \mathrm{CH}^{-1}$.

Comparing the TPO profiles for the used catalysts in the three reactions, we can observe that the coke deposited on the catalyst used in MTH and DTH reactions is mainly coke II, whereas for $\mathrm{CTH}$ reaction, the amount of coke I is similar to that of coke II after the initial $35 \mathrm{~min}$, and increase faster after that up to $240 \mathrm{~min}$. This result is illustrative of the fact that in the CTH reaction, the formation and growth of coke is faster than the rest of the reactions. It has been repeatedly proved that within agglomerated catalysts based on H-ZSM-5 zeolite having a mesoporous matrix, the growth rate of coke II is limited by the micropore topology of the H-ZSM- 5 zeolite, whereas that of coke $I$ is less limited. This has been confirmed in hierarchical zeolites too. ${ }^{[63]}$ This effect is due to the fact that in the disordered mesoand macropores of the matrix the growth of coke has less steric hindrance. Furthermore, the presence of water in the MTH and DTH reactions regulates the capability of the acid sites to condensate HCP aromatics into coke, by sweeping out coke precursors. In these circumstances, the total content of coke increases slightly from 35 up to 240 min on stream in the MTH reaction (from $1.1 \mathrm{wt} \%$ up to $1.2 \mathrm{wt} \%$ ), this increase is higher for the DTH reaction (from 1.2 up to $1.7 \mathrm{wt} \%$ ) and doubles for the $\mathrm{CTH}$ reaction (from 1.5 up to $3.0 \mathrm{wt} \%$ ). Due to this faster coke II formation and growth, the conversion of chloromethane drops to a much higher extent under the same conditions (Figure 2b).

The results of Figure 8 correspond to the TPO profiles analyzed by simultaneous $\mathrm{MS}\left(\mathrm{CO}_{2}\right.$ signal evolution $)$ and FTIR spectroscopy (derivative of the representative absorbance bands, $\mathrm{dA} / \mathrm{dt}$ ). The assignment of those bands has been described in the previous section. The $\mathrm{CO}_{2}$ signal evolution during TPO profiles in Figure 8 are show similar coke amount trends as in Figures $7 \mathrm{~d}$ : CTH > DTH > MTH. It is important to indicate that the MS-FTIR/TPO profiles have been obtained without a previous TPD, as it happened for the TG/TPO profiles. When compared the $\mathrm{CO}_{2}$ signal with the FTIR bands evolutions, we can confirm that the aliphatic nature of coke I and the more aromatic one of coke II. The evolution of the $\mathrm{dA} / \mathrm{dt}$ show the selective combination of pyrolysis and combustion occurring during the TPO. Thus, aliphatics are dehydrogenated first (< $250{ }^{\circ} \mathrm{C}, \mathrm{CO}_{2}$ signal is unchanged) into olefins and aromatics, and then combusted together with aromatics $\left(>250{ }^{\circ} \mathrm{C}\right)$ as the fractions of coke (I and II) at the corresponding $\sim 420$ and $520{ }^{\circ} \mathrm{C}$, respectively. In addition to what stated before, these results certify that the coke $\mathrm{I}$ is more aliphatic and deposited on the external part of the zeolite whereas coke II is more aromatic and affects more the micropores of the catalyst. Thus, the trends of surface degradations shown in Figure 6 seems to match the amounts and locations of coke displayed in Figures 7 and 8. 


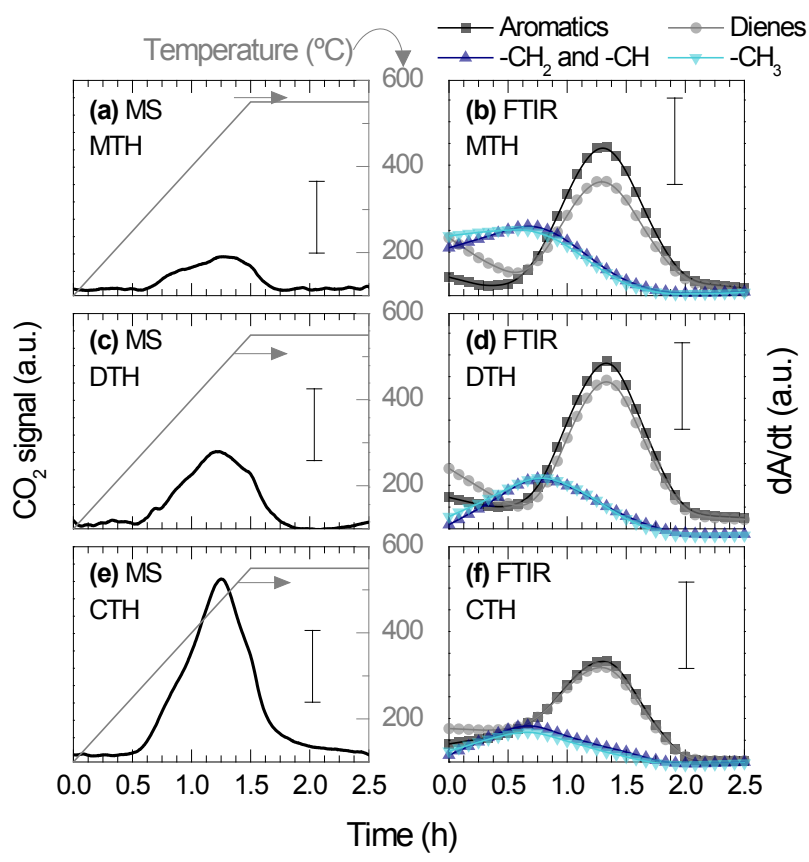

Figure 8. Evolution of representative $\mathrm{FTIR}$ bands and $\mathrm{CO}_{2} \mathrm{MS}$ signal during the TPO of spent catalysts after the (a and b) MTH, (c and d) DTH and (e and f) $\mathrm{CTH}$ reactions. Reaction conditions: $400{ }^{\circ} \mathrm{C} ; 1.5 \mathrm{~atm} ; \mathrm{n}_{\mathrm{BAS}} / \mathrm{F}=196.3 \mu \mathrm{mol}_{\mathrm{BAS}}$ h molcH ${ }^{-1}, 240$ min on stream.

\section{Molecular scale modelling}

Figure 9 shows the reaction energy diagram obtained by the molecular simulations for methanol, DME and chloromethane reacting with an acid site of the H-ZSM-5 zeolite, together with three snapshots of the reaction states for the methanol case: free reactant and acid site, transition state (TS) and product formation (methoxy and water in this case). The energy values are given in $\mathrm{kcal} \mathrm{mol}^{-1}$, taking as reference energy the sum of energies of the isolated reactants. It must be noted that only a portion of the H-ZSM-5 unit cell is showed in Figure 9 for a better view, yet a full zeolite model was used. Such model, more realistic than the common 3-site or 5-site cluster models used in quantum mechanical (QM) simulations, is possible due to the use of ReaxFF empirical potential, with the possible cost of less quantitative energy prediction. Previous comparison between ReaxFF and QM of a H-ZSM-5 acid site methylation by methanol in 3-site and 128-site clusters report an underestimation of the activation energy of $\sim 10 \%$ by ReaxFF. ${ }^{[64]}$ However, the QM energy barrier calculated in that work at a DFT B3LYP/6-31g(d,p) level of theory is $40 \mathrm{kcal} \mathrm{mol}^{-1}$, about $13 \mathrm{kcal}$ $\mathrm{mol}^{-1}$ smaller than those obtained consistently by other authors for a $3 / 5$-site clusters using the same DFT exchange correlation functional but different bases sets $\left(53.5^{[65]}, 55.7^{[66]}, 51.4^{[67]}\right.$ and $52.2^{[68]}$ ). In addition, previous studies used the STQN method to locate transition state while here the NEB approach was employed, which commonly gives a better sampling of the Potential Energy Surface (PES) and may lead to a lower TS energy. Therefore, the computed activation energies for the formation of methoxy species formation and methylation are considerably lower than those reported in the literature, and in absence of a detailed study should be taken as qualitative values for comparison between methanol, chloromethane and dimethyl ether. It must be also kept in mind that this approach computes activation potential energy barriers, so the contribution from thermodynamic variables, specially temperature, is not considered. Advanced sampling methods like the blue moon ensemble are required in this sense. ${ }^{[69]}$

To determine the initial stable configuration for the reactants and products a short annealing was carried out using methanol as a probe molecule, reducing the temperature from $300 \mathrm{~K}$ to $1 \mathrm{~K}$ in 100 ps. With those configurations as initial and final reaction states, the Nudge Elastic Band simulation was performed with 32 replicas. A single energy barrier was found for chloromethane and dimethyl ether conversion, and two for methanol (Figure 9). One of them is very small, $4.9 \mathrm{kcal} \mathrm{mol}^{-1}$, and corresponds to a rotation from the most favorable adsorption configuration to the starting point for the methylation reaction. Dimethyl ether may also present a similar transition, yet it was not found in the present study. The reaction energy barriers are 17.2, 13.5 and $62.0 \mathrm{kcal} \mathrm{mol}^{-1}$, for MTH, DTH and CTH reactions, respectively. From these results, it is clear that methanol and dimethyl ether react quickly with the zeolite acid site, with a lower energy barrier for the latter, in good agreement with previous results. ${ }^{[68,70]} \mathrm{CTH}$ reaction shows a considerably higher energy barrier, more than 3 times larger than the aforementioned, which is in agreement with the much slower experimental conversion displayed in Figure 2. In addition, our calculations indicate that the products (methylated zeolite and methoxy species or $\mathrm{HCl}$ ) are thermodynamically unfavorable compared to the reactants, and the energy barrier for the reversible reaction is less than half $\left(17.5 \mathrm{kcal} \mathrm{mol}^{-1}\right)$ so the reaction is unlikely to produce methylated sites that would remain stable in time. To gain more insight on the origin of such a large energy barrier difference, the DNEB intermediates geometries were analyzed. The most significant difference was found in the $\mathrm{H}-\mathrm{O}_{z e o}$ distance evolution. For $\mathrm{MTH}$ and $\mathrm{DTH}$, the $\mathrm{H}-\mathrm{O}_{\text {zeo }}$ distance increases smoothly from $\sim 1.1 \AA$ to dissociation distances $>3 \AA$, while for $\mathrm{CTH}$ there is a sharp increase form the initial equilibrium distance to dissociation. We attribute this to the possibility of forming a hydrogen bond between the MTH and DTH byproducts (water and methanol respectively) during the reaction. The hydrogen bond is not possible with a $\mathrm{Cl}$, and hence the reaction must take place abruptly. Such key role of hydrogen bonding in zeolite catalytic activity has been already observed in previous computational studies. ${ }^{[71]}$

To investigate the molecular modelling of the deactivation step during MTH, DTH and CTH reactions via coke formation, the reaction of anthracene methylation was simulated. Figure 10 shows the reaction energy diagram and the atomic configuration for the MTH reaction. The reaction taken is a test of coke growth by homogeneous methylation. ${ }^{[72]}$ 

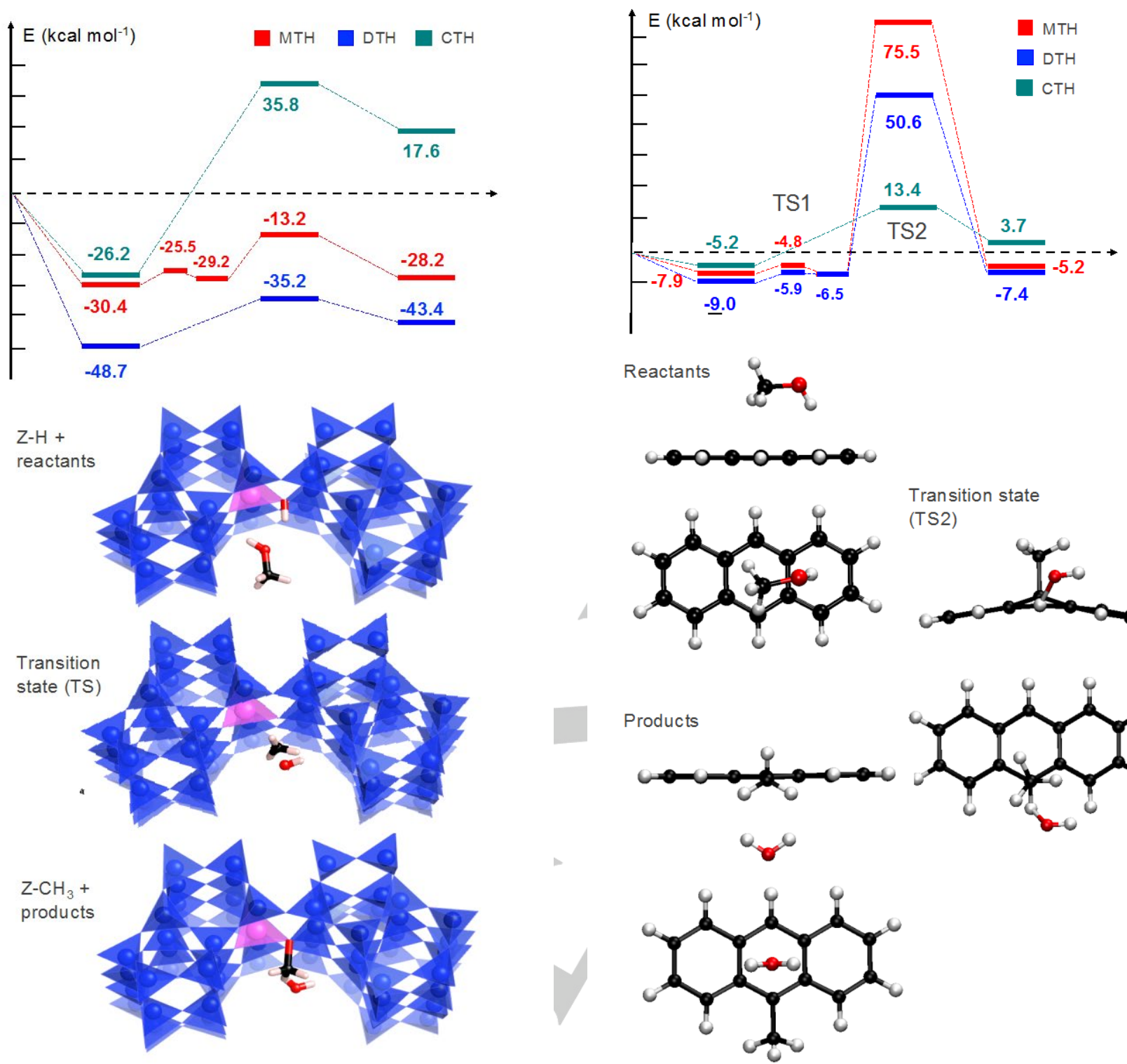

Transition state (TS2)
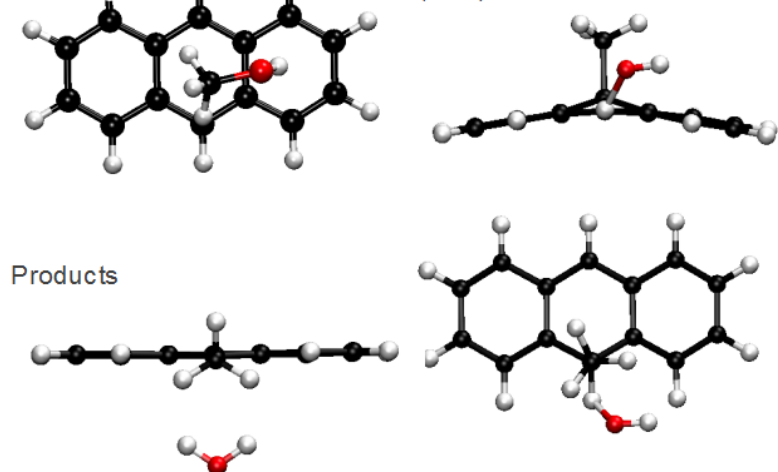

Figure 9. Reaction energy diagram for the reaction of methanol, dimethyl ether or chloromethane on an acid site of the H-ZSM-5 zeolite.

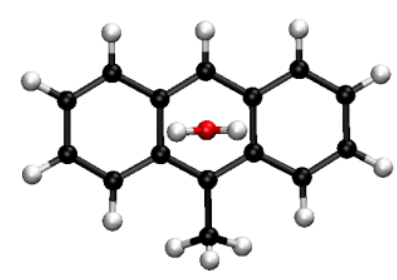

Figure 10. Energy diagram for the methylation of an anthracene molecule in the MTH, DTH and CTH reactions.

The initial stable configuration for the reactants was determined as in the previous case by annealing method, using methanol as a probe molecule. The result indicates that methanol is preferentially coordinated to the central ring of the anthracene. From there, we targeted a chemical reaction in the equivalent positions 9 or 10, most favorable ones for an electrophilic attack. The final structure was set ad-hoc, consisting in a methylated anthracene and the remaining product $\left(\mathrm{H}_{2} \mathrm{O}, \mathrm{HCl}\right.$ or methanol) in the opposite site of the initial attack configuration. With those initial and final structures (see Figure 10) the Nudge Elastic Band simulation was performed with 32 replicas between the product and the reactant. For methanol and dimethyl ether, the reaction follows a similar path.

The molecules rotate slightly to orient their oxygen atom towards the anthracene. The energy barrier for the rotation (TS1) is relatively small, $3.1 \mathrm{kcal} \mathrm{mol}^{-1}$ for both methanol and dimethyl ether. Chloromethane did not present such energy barrier as it does not need to rotate to reach the optimal orientation for the reaction. The next step is common for the three reactants; the $O$ from methanol/dimethyl ether and the $\mathrm{Cl}$ from chloromethane coordinates with the $\mathrm{H}$ atom in position 10 from the anthracene and the $C$ from the methyl group to the $C$ in position 10 from the anthracene. The reactions proceeds releasing the $\mathrm{H}$ from anthracene and substituting it with the methyl. The energy barrier in this case (TS2) is considerably different. For CTH reaction, the modelling yields a barrier of $18.6 \mathrm{kcal} \mathrm{mol}^{-1}$, and for 
MTH and DTH reactions 82.0 and $57.1 \mathrm{kcal} \mathrm{mol}^{-1}$ respectively. These values are in good qualitative agreement with the experimental data of formation and growth of coke (Figures 5 , $7 \mathrm{~d}$ and 8), showing that the chloromethane reaction to form coke is considerably more favorable, then and importantly is dimethyl ether and finally methanol.

Thus, the molecular scale simulations perfectly match the kinetic and deactivation observations: The reactions are kinetically favored in the order DTH > MTH $>\mathrm{CTH}$, whereas the order of deactivating species formation and growth is CTH >> DTH > MTH.

\section{Discussion}

We have studied the differences among the use of methanol, dimethyl ether or chloromethane as feedstock to produce hydrocarbons using identical reaction conditions. Our comparison approach is based on providing equivalent amounts of $\mathrm{CH}_{3}$ groups in each feedstock over the same number of active sites in the HZSM- 5 catalyst. The analysis of our results proves the mechanistic similarities in the methanol, dimethyl ether and chloromethane transformation to hydrocarbons. However, we proved significant differences at kinetic, thermodynamic and deactivation level. Figure 11a summarizes the main reaction pathways, showing that the mechanism of hydrocarbon formation is ruled by the well-accepted dual-cycle mechanism for the three reactions whereas the mechanism of coke formation has a direct pathway from chloromethane that does not involve HCP species intermediates.

In this mechanistic scheme there are three main kinetic steps taking place: (i) initiation, (ii) propagation and (iii) deactivation. In the initiation step, the formation of methoxy species and C-C bonds lead to the formation of olefins and aromatics (HCP species) on the acid sites. In the propagation step, $\mathrm{CH}_{3}$ groups from methanol, dimethyl ether or chloromethane can be directly added to these HCP species through a condensation reaction that generates water or $\mathrm{HCl}$ and leads to the methylation of $\mathrm{HCP}$ species and subsequent reactions of dealkylation or cracking to yield light olefins as primary products in two distinctive cycles according to the nature of these HCP species: olefin or aromatic. ${ }^{[73,74]}$ In the olefin cycle, light olefins can also suffer oligomerization reactions and further cyclization and hydrogen transfer reactions yielding $\mathrm{C}_{5+}$ aliphatics, aromatics and paraffins These latter reactions link both cycles. Aromatic cycle involves, at the same time side chain (SD) and paring reactions, being the latter more favorable in a H-ZSM-5 zeolite. ${ }^{[26]}$ The degradation of aromatic HCP species yields coke that gives rise to the deactivation step. However, chloromethane can also form coke by a direct pathway.

The differences between DTH and MTH reactions are the faster kinetics of methylation and aromatic cycle condensation of the former, which have been corroborated by molecular modelling simulations (Figures 9 and 10).
Figure $11 \mathrm{~b}$ summarizes the main differences found between oxygenated $\left(\mathrm{CH}_{3} \mathrm{O}-\mathrm{R}\right)$ and chlorinated $\left(\mathrm{CH}_{3} \mathrm{Cl}\right)$ feeds based on our experimental and modelling results. Firstly, we highlight that the initiation and propagation steps are faster in the conversion of dimethyl ether and methanol whereas these are slower in the conversion of chloromethane. This is based on the following experimental observations: (1) the conversion of $\mathrm{CTH}$ reaction is lower and it reaches its maximum after $20 \mathrm{~min}$ on stream whereas MTH and DTH reactions reach full conversion since the first 5 min on stream (Figure 2a); and (2) the HCP species are less evolved for the CTH reaction at $20 \mathrm{~min}$ on stream (Figure 4) or using equivalent feed of each reactant (Figure 5a), indicating a lower methylation kinetic and accumulation rate. The slower kinetics of initiation and propagation of chloromethane lead to $\mathrm{HCP}$ species that are less evolved or aged. Fickel et al. ${ }^{[16]}$ proved that the amount of HCP species increases with chloromethane conversion during the induction period in the CTH reaction over SAPO-34 catalysts. Olsbye et al. ${ }^{[42]}$ explained that the lower chloromethane conversion compared to that of methanol is due to the differences between the proton affinities of both reactants, which is thermodynamically influenced, and this leads to a lower coverage of acid sites with methyl species from chloromethane in a SAPO-34 catalyst. Our theoretical results (Figure 9) confirm that chloromethane has a three-time larger energy barrier to react with an active site in a HZSM-5 zeolite to form adsorbed methyl species compared to that of methanol or dimethyl ether. Thus, this thermodynamic barrier is responsible for the slower induction and propagation events in the $\mathrm{CTH}$ reaction.

A major player in the overall kinetic and deactivation performance of these reactions is $\mathrm{H}_{2} \mathrm{O}$ in the reaction media. Many authors have investigated the role of water on the primary products formation, ${ }^{[75,76]}$ and the entire reaction network. ${ }^{[77]}$ This molecule is present in greater amounts in the MTH reaction and it is a "co-cause" of the slower coke formation than DTH reaction. On the other side, $\mathrm{H}_{2} \mathrm{O}$ is substituted by $\mathrm{HCl}$ in the $\mathrm{CTH}$ reaction. The formed $\mathrm{HCl}$ in the $\mathrm{CTH}$ reaction is known to cause much severer dealumination of the catalyst than water, ${ }^{[43]}$ but it can be controlled by using temperatures as the one used in this work.

The increase of the chloromethane conversion, despite the slower induction and propagation events, is truncated by the rapid catalyst deactivation that is evident after $35 \mathrm{~min}$ on stream (Figure $2 \mathrm{~b}$ ). We verified that this catalyst deactivation is due to the rapid coke formation located at the mesoporous structure of the catalyst (Figures 5-8) that block the access to the zeolite pores decreasing the diffusion of reactants and products. Also, this coke comes from another pathway different from the degradation of HCP species as it is commonly accepted to explain the catalyst deactivation during the methanol or dimethyl ether conversion. ${ }^{[27]}$ Thus, chloromethane is able to react homogeneously to methylate coke precursors giving rise to a rapid increase of coke in the mesoporous structure of the catalyst. This was verified by our theoretical results (Figure 10), demonstrating that an anthrancene molecule is more prone to 
be methylated by chloromethane than by methanol or dimethyl ether in a homogeneous reaction (non-catalyzed).

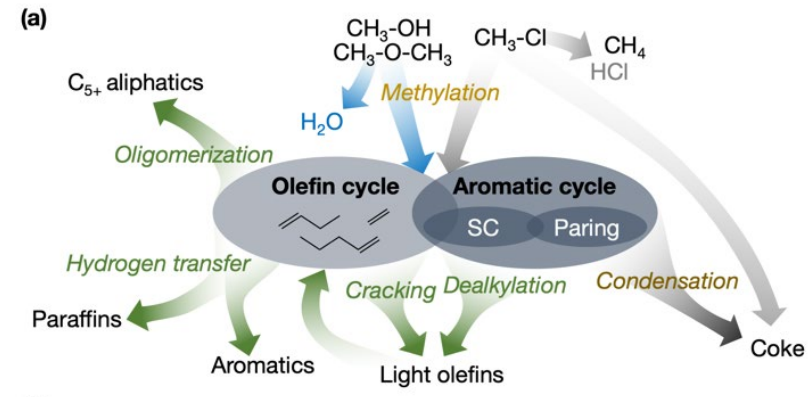

(b)

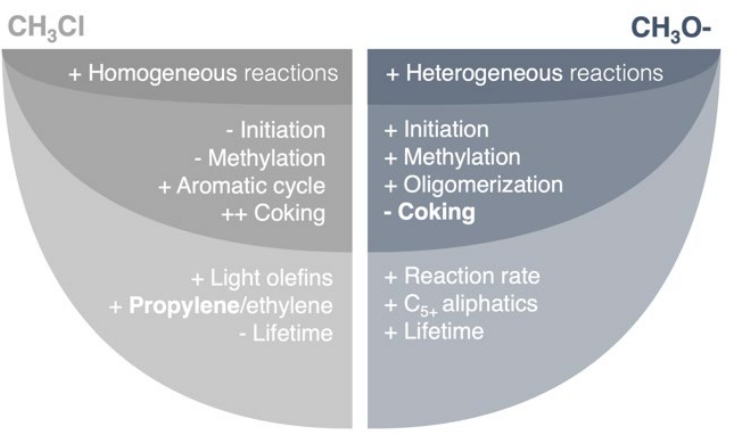

Figure 11. (a) Kinetic scheme of the MTH, DTH and CTH reactions and (b) main differences among the reactant used.

The great experimental divergence of conversion observed for the MTH, DTH and CTH under the same conditions makes difficult to compare the processes on a mechanistic ground. We have solved this issue comparing experimental results at different conversion values and with molecular modelling simulations. One key difference among the process is the change of the reaction medium composition, which affects the product distribution and deactivation. ${ }^{[78]}$ At similar level of conversions, DTH and MTH reactions have similar product distribution. However, at intermediate conversion, chloromethane shows faster aromatic cycle propagation leading to greater yields of light olefins and propylene in particular, making the process very interesting at these conditions from industrial perspective. By all means, HCP species has a pivotal role producing the main interesting products (light olefins and propylene) and deactivating species (coke).

\section{Conclusions}

We have investigated the role of feeding methanol, dimethyl ether or chloromethane to produce hydrocarbons (namely MTH, DTH and CTH reactions, respectively) on a H-ZSM-5 zeolite catalyst and using similar reaction conditions. The role has been evaluated in terms of experimental and theoretical kinetic and deactivation performances. The experiments have been performed in fixed bed and operando FTIR reactors under relevant conditions, and the products and used catalyst have been characterized in detail.

All processes occur through the main reaction pathways of the dual cycle mechanism coupled with the parallel reactions of light olefins (hydrogen transfer, oligomerization and condensation). However, the different methylation rate of each reactant lead to the observed and modelled production rates of hydrocarbons, which are in the order DTH > MTH > $>\mathrm{CTH}$. The faster reaction rate and lower concentration of water in the reaction medium of DTH compared with the MTH process, lead to faster conversion of the hydrocarbon pool hydrocarbons in the former process and the formation of more methylated and condensed aromatics, that are ultimately coke. At the same time, chloromethane suffer parallel degradation reactions (not so important for methanol and dimethyl ether) that yield methane and coke. Thus, the trend of deactivation is in the order CTH $>>$ DTH $>$ MTH.

The coke formation and growth mechanisms among the three reactions studied are the same, with two fractions: (i) coke I, deposited on the mesopores of the matrix and with a relatively disordered and aliphatic nature and (ii) coke II, deposited in the micropores on their mouth and with a condensed aromatic nature. Coke II is the main player in catalyst deactivation. However, coke I can lead to the complete blockage to the acid sites at relatively high content. In our case, this last effect is only observed for $\mathrm{CTH}$ reaction.

Molecular simulations at the empirical level were also carried out to support the experimental observations. The obtained reaction energy barriers for the methylation of a H-ZSM-5 acid site and the methylation of anthracene follow the same trend as the experiments, corroborating the interpretation of the experimental results.

The disadvantages of the $\mathrm{CTH}$ reaction, namely slower kinetics and faster deactivation, can be conveyed into a more favorable setting: for the same space time as the conversion of chloromethane is lower, the selectivity of light olefins and the ratio propylene/ethylene is significantly higher.

\section{Experimental Section}

\section{Catalyst properties}

The commercial zeolite, supplied in its ammonium form by Zeolys International $\left(\mathrm{SiO}_{2} / \mathrm{Al}_{2} \mathrm{O}_{3}=80\right)$, has been subjected to a calcination step $\left(550{ }^{\circ} \mathrm{C}, 3 \mathrm{~h}\right)$ in order to remove the ammonia and obtain the acid form. Natural bentonite supplied by Exaloid and exchanged with $\mathrm{NH}_{4} \mathrm{NO}_{3} 1 \mathrm{M}$ (Panreac, $98 \%$ ) has been used as binder (30 wt\%), and $\alpha$-alumina (Prolabo, calcined at $1000{ }^{\circ} \mathrm{C}$ ) as inert filler (45 wt\%). The catalyst particles have been obtained by wet extrusion, using a high-pressure hydraulic piston, through $0.8 \mathrm{~mm}$ diameter holes. The extrudate materials obtained were dried: (i) at room temperature for $24 \mathrm{~h}$, and (ii) later, in an oven at $110{ }^{\circ} \mathrm{C}$ for $24 \mathrm{~h}$. Then the catalyst was sieved selecting a particle size between 0.15 and $0.3 \mathrm{~mm}$. Finally, the catalyst was calcined at $575{ }^{\circ} \mathrm{C}$ for $3 \mathrm{~h}$. This temperature was reached following a ramp of $5{ }^{\circ} \mathrm{C}$ 
$\min ^{-1}$. This methodology has been proved as important to assure a realistic, scalable and stable MTH or DTH reactions. ${ }^{[79,80]}$

The catalyst was characterized in terms of (i) surface area and (ii) acidity. Surface area and porous structure has been determined by $\mathrm{N}_{2}$ adsorption-desorption (Micromeritics ASAP 2010). The micropore volume corresponds to the active phase, whereas the volume of meso- and macropores corresponds to the matrix of the catalyst. The total acidity and acid strength of the catalysts have been determined by monitoring the adsorption-desorption of $\mathrm{NH}_{3}$, by combining the techniques of thermogravimetric analysis-differential scanning calorimetry and temperature-programmed desorption using a Setaram TG-DSC calorimeter connected on line with a Thermostar mass spectrometer from Balzers Instruments. The Brønsted and Lewis acid site concentration (BAS and LAS) has been determined by analyzing the region of 1400 $1700 \mathrm{~cm}^{-1}$ in the FTIR spectrum of adsorbed pyridine, which has been obtained using a Specac catalytic chamber and a Nicolet 6700 FTIR spectrometer. BAS/LAS at $150^{\circ} \mathrm{C}$ has been determined from the ratio between the intensity of pyridine adsorption bands at $1545 \mathrm{~cm}^{-1}$ and $1450 \mathrm{~cm}^{-1}$ and considering the molar extinction coefficients of both adsorption bands $\varepsilon_{\mathrm{B}}=1.67 \mathrm{~cm} \mathrm{\mu mol}^{-1}$ and $\varepsilon_{\mathrm{L}}=2.22 \mathrm{~cm} \mathrm{\mu mol}^{-1}$

The characterization results yield the following catalytic properties: surface area, $203 \mathrm{~m}^{2} \mathrm{~g}^{-1}$; micropore surface area, $106 \mathrm{~m}^{2} \mathrm{~g}^{-1}$; meso- and macropore surface area, $97 \mathrm{~m}^{2} \mathrm{~g}^{-1}$; average pore diameter, $79 \AA$; total acidity, $172\left(\mu \mathrm{mol}\right.$ of $\left.\mathrm{NH}_{3}\right) \mathrm{g}^{-1}$; average acid strength, $124 \mathrm{~kJ}\left(\mathrm{~mol} \text { of } \mathrm{NH}_{3}\right)^{-}$ 1; BAS/LAS, $1.01 \mathrm{~mol} \mathrm{~mol}^{-1}$.

\section{Kinetic experiments}

Experiments were carried out by feeding methanol (Sigma-Aldrich, 99.8\%), dimethyl ether (Air liquid, 99.9\%), and chloromethane (Alpha Gaz, $99.999 \%$ ) with $\mathrm{He}$ as diluent $(15 \mathrm{~mol} \%)$ in an isothermal fixed bed reactor under the following operating conditions: $400^{\circ} \mathrm{C}$; $1.5 \mathrm{~atm}$; space time, $\mathrm{n}_{\mathrm{BAS}} / \mathrm{F}=6.49-2048 \mu$ mol$_{\mathrm{BAS}} \mathrm{h} \mathrm{mol}_{\mathrm{CH}_{3}{ }^{-1}}$. The purity of these reactants have been found to have a critical role in the overall process performance. ${ }^{[81]}$ The bed consists of a mixture of catalyst and $\mathrm{SiC}$ (inert and diluent, supplied by Prolabo). The $\mathrm{HCl}$ formed during the $\mathrm{CTH}$ reaction was removed by using two fixed bed adsorption reactors in series, made of a mixture of $\mathrm{CaCO}_{3}$ (95 wt\%) and Laponite (5 wt\%). These materials were calcined at $800{ }^{\circ} \mathrm{C}$ thereby increasing the surface area and adsorption capacity. The gases from these catalytic beds pass through a particle filter of $5 \mu \mathrm{m}$ mesh diameter and subsequently are cooled down to $170^{\circ} \mathrm{C}$. A fraction of the product stream is diluted in a $\mathrm{He}$ stream and continuously analyzed in a micro-chromatograph Varian CP. 4900 GC. The remaining reaction stream is partially condensed in a Peltier cell at $0{ }^{\circ} \mathrm{C}$ and the uncondensed gas flow is vented.

The conversions of methanol, dimethyl ether or chloromethane $(X)$ and different selectivity ( $\mathrm{Si}$ ) and yields (Yi) have been calculated using the molar flow rates of reactants and products, which are regardless the reactant: methane, $\mathrm{C}_{2}-\mathrm{C}_{4}$ light olefins, $\mathrm{C}_{5+}$ aliphatics $\left(\mathrm{C}_{5+} \mathrm{HC}\right), \mathrm{C}_{2}-\mathrm{C}_{4}$ light paraffins, aromatics (benzene, toluene and xylenes or the so-called BTX fraction).

Besides the fixed bed reactor, the reactions were studied by in an in-situ Fourier transformed infrared (FTIR) spectroscopy cell. This setup is similar to the one used for characterizing the BAS/LAS of the fresh catalyst: Specac catalytic chamber and a Nicolet 6700 FTIR spectrometer. The samples of fresh catalysts $(\sim 20 \mathrm{mg})$ were pelletized applying pressure equivalent to 10 ton $\mathrm{cm}^{-2}$ for $10 \mathrm{~min}$. The catalyst was heating to $450{ }^{\circ} \mathrm{C}$ with a $10{ }^{\circ} \mathrm{C} \mathrm{min}$ m $^{-1}$ ramp under vacuum for about $60 \mathrm{~min}$, to clean the surface and remove impurities. After that, the temperature is stabilized at $400{ }^{\circ} \mathrm{C}$ (reaction temperature), are performed successive $1 \mathrm{~min}$ pulses of reactant (methanol, dimethyl ether or chloromethane), subsequently a feed of $\mathrm{He}(5 \mathrm{~min})$ to remove physisorbed and the corresponding spectrum is recorded. These steps are repeated until the saturation of FTIR bands reach a steady state, which has occurred after 15 pulses.

\section{Used catalyst characterization}

The retained species on the used catalyst fraction has been extracted by catalyst disaggregation, liquid extraction with $\mathrm{CH}_{2} \mathrm{Cl}_{2}$ and subsequent analysis in a GC-MS. The experimental procedure consists in grinding $100-400 \mathrm{mg}$ of sample and dissolving the catalyst structure with $\mathrm{HF}$ (Merck, $40 \%$ by mass in $\mathrm{H}_{2} \mathrm{O}$ ). $\mathrm{CH}_{2} \mathrm{Cl}_{2}$ is added in three stages of $10 \mathrm{~mL}$ each, part of the solvent is evaporated to obtain a suitable amount of sample $(\sim 2.5 \mathrm{~mL}$ ) for the analysis in a GC-MS (Shimadzu GCMSQP2010 and GC-2010 gas chromatograph), with a BPX5 column of $50 \mathrm{~m}$ $\times 0.22 \mathrm{~mm} \times 0.25 \mu \mathrm{m}$.

The temperature programmed desorption (TPD) and oxidation (TPO) of the used catalyst were performed with a TGA Q5000TA thermobalance (Thermo Scientific) following the procedure: (1) scan of the sample with $\mathrm{N}_{2}$ stream to remove impurities; (2) combustion with air at $550{ }^{\circ} \mathrm{C}$ with a temperature ramp of $5{ }^{\circ} \mathrm{C} \mathrm{min}{ }^{-1}$ followed by isothermal conditions for 90 min (to ensure complete combustion of coke); (3) the sample is cooled with a ramp of $15^{\circ} \mathrm{C} \min ^{-1}$ to $250{ }^{\circ} \mathrm{C}$.

The TPO was also analyzed with solid in-situ FTIR spectroscopy, using similar equipment described before: Specac catalytic chamber and a Nicolet 6700 FTIR spectrometer. The used catalyst sample $(10 \mathrm{mg})$ was pelletized with $\mathrm{KBr}(150 \mathrm{mg}$, purity $>99 \%)$. The sample was degassed at $100{ }^{\circ} \mathrm{C}$ for $1 \mathrm{~h}$. Then, air is allowed to pass through the chamber with a flow-rate of $60 \mathrm{~mL} \mathrm{~min}-1$ and temperature is raised linearly at $5^{\circ} \mathrm{C} \mathrm{min}{ }^{-1}$ to $550{ }^{\circ} \mathrm{C}$, maintaining this temperature for $1 \mathrm{~h}$. Simultaneously, the signal of $\mathrm{CO}_{2}(\mathrm{~m} / \mathrm{z}=44)$ is recorded on a mass spectrometer (OmniStar ThermoStar)

\section{Molecular scale simulations}

The molecular scale simulations were performed at the empirical level of theory, using the ReaxFF force field. ${ }^{\left[{ }^{[2]}\right.}$ ReaxFF uses bond-order and bond-length/angle dependent energy expressions to simulate the shortrange interactions between atoms, as well as an adaptive charge scheme to compute on the fly the atomic charges for the long-range coulomb forces. Such formalism allows bond breaking, bond formation, and accurate energy description of transition states, giving access to the study of chemical reactions in systems orders of magnitude larger than ab-initio methods.

Simulations were performed to determine the reaction energy barriers of methanol, chloromethane, and dimethyl ether deactivation by coke formation outside the zeolite and olefin conversion catalyzed by H-ZSM- 5 zeolite acid sites. The simulations were done with the code GULP version 4.5. ${ }^{[83]}$ First, a short Molecular Dynamics (MD) simulation in the canonical ensemble was done during 10 ps at low temperature $\left(243{ }^{\circ} \mathrm{C}\right)$ to determine an initial stable configuration for the reactions. Such test was only done for methanol, and the obtained configuration was used for chloromethane and dimethyl ether changing the $\mathrm{OH}$ group by the corresponding moiety $\left(\mathrm{Cl}\right.$ or $\left.\mathrm{CH}_{3}\right)$. The energy barriers were determined using the Double Nudged Elastic Band (DNEB) method, ${ }^{[84]}$ with a spring constant of $50 \mathrm{kcal} \mathrm{mol}^{-1}$. The number of replicas varied from system to system, with no less than 16 and no more than 32. After an initial DNEB run without intermediate replicas, the generated path was analysed, and 
1-2 intermediate replicas were set ad-hoc to find a lower energy minimum energy reaction path. The energy minimization was done using the BFGS algorithm.

The MFI zeolite structure obtained from the database of zeolite structures of the international zeolite association (IZA) was used to mimic the commercial H-ZSM-5 zeolite as catalyst. A single Al for Si replacement was done in the $\mathrm{T} 7$ site, reported to be the most stable substitution site by $X R D,{ }^{[85]}$ and DFT calculations, ${ }^{[86]}$ with a proton to counterbalance the charge creating the acid reactive site. The artificial zeolite manipulation and molecule construction were performed with Crystalmaker 9.2.

\section{Acknowledgements}

The financial support of this work was undertaken by the Ministry of Economy, Industry and Competitiveness of the Spanish Government (CTQ2016-79646-P, some co-founded with ERDF funds), and the Basque Government (Project IT91216). José Valecillos is thankful for his fellowship by the Ministry of Economy, Industry and Competitiveness of the Spanish Government (BES-2014-069980). The authors are thankful for technical and human support provided by IZO-SGI SGIker of UPV/EHU and European funding (ERDF and ESF).

Keywords: Methanol-, dimethyl ether- and chloromethane-tohydrocarbons $\cdot$ ZSM- 5 zeolite $\cdot$ coke formation $\cdot$ catalyst deactivation $\cdot$ halide to hydrocarbons

\section{References}

[1] X. Xu, Y. Liu, F. Zhang, W. Di, Y. Zhang, Catal. Today 2017, 298, 61-68.

[2] G. Perkins, T. Bhaskar, M. Konarova, Renew. Sustain. Energy Rev. 2018 90, 292-315

[3] G. Lopez, M. Artetxe, M. Amutio, J. Bilbao, M. Olazar, Renew. Sustain. Energy Rev. 2017, 73, 346-368.

[4] D. Yadav, R. Banerjee, Renew. Sustain. Energy Rev. 2016, 54, 497-532.

[5] I. Amghizar, L. A. Vandewalle, K. M. Van Geem, G. B. Marin, Engineering 2017, 3, 171-178.

[6] S. M. Sadrameli, Fuel 2015, 140, 102-115.

[7] S. M. Sadrameli, Fuel 2016, 173, 285-297.

[8] P. A. Alaba, A. Abbas, W. M. W. Daud, J. Clean. Prod. 2017, 140, 12981312.

[9] A. Álvarez, A. Bansode, A. Urakawa, A. V Bavykina, T. A. Wezendonk, M. Makkee, J. Gascon, F. Kapteijn, Chem. Rev. 2017, 117, 9804-9838.

[10] R. Lin, A. P. Amrute, J. Pérez-Ramírez, Chem. Rev. 2017, 117, 41824247.

[11] P. Tian, Y. Wei, M. Ye, Z. Liu, ACS Catal. 2015, 5, 1922-1938.

[12] A. S. Al-Dughaither, H. De Lasa, Fuel 2014, 138, 52-64.

[13] M. Ibañez, P. Pérez-Uriarte, M. Sánchez-Contador, T. Cordero-Lanzac, A. T. Aguayo, J. Bilbao, P. Castaño, Catalysts 2017, 7, 254.

[14] G. Nasser, T. Kurniawan, K. Miyake, A. Galadima, Y. Hirota, N. Nishiyama, O. Muraza, J. Nat. Gas Sci. Eng. 2016, 28, 566-571.
[15] M. Gamero, B. Valle, P. Castaño, A. T. Aguayo, J. Bilbao, J. Ind. Eng. Chem. 2017, DOI 10.1016/j.jiec.2017.12.042.

[16] D. W. Fickel, K. D. Sabnis, L. Li, N. Kulkarni, L. R. Winter, B. Yan, J. G. Chen, Appl. Catal. A Gen. 2016, 527, 146-151.

[17] S. Kim, Y. T. Kim, A. Hwang, K.-W. Jun, G. Kwak, ChemCatChem 2017, 9, 1569-1573.

[18] K. Hemelsoet, A. Nollet, M. Vandichel, D. Lesthaeghe, V. Van Speybroeck, M. Waroquier, ChemCatChem 2009, 1, 373-378.

[19] D. M. McCann, D. Lesthaeghe, P. W. Kletnieks, D. R. Guenther, M. J. Hayman, V. Van Speybroeck, M. Waroquier, J. F. Haw, Angew. Chemie Int. Ed. 2008, 47, 5179-5182.

[20] S. Ilias, A. Bhan, ACS Catal. 2013, 3, 18-31.

[21] M. Bjørgen, S. Svelle, F. Joensen, J. Nerlov, S. Kolboe, F. Bonino, L. Palumbo, S. Bordiga, U. Olsbye, J. Catal. 2007, 249, 195-207.

[22] R. Khare, A. Bhan, J. Catal. 2015, 329, 218-228.

[23] S. Ilias, R. Khare, A. Malek, A. Bhan, J. Catal. 2013, 303, 135-140.

[24] J. F. Haw, W. Song, D. M. Marcus, J. B. Nicholas, Acc. Chem. Res. 2003 36, 317-326.

[25] S. N. Khadzhiev, M. V Magomedova, E. G. Peresypkina, Pet. Chem. 2014, 54, 245-269.

[26] C. Wang, Y. Chu, A. Zheng, J. Xu, Q. Wang, P. Gao, G. Qi, Y. Gong, F. Deng, Chem. - A Eur. J. 2014, 20, 12432-12443.

[27] U. Olsbye, S. Svelle, K. P. Lillerud, Z. H. Wei, Y. Y. Chen, J. F. Li, J. G. Wang, W. B. Fan, Chem. Soc. Rev. 2015, 44, 7155-7176.

[28] D. Rojo-Gama, M. Signorile, F. Bonino, S. Bordiga, U. Olsbye, K. P Lillerud, P. Beato, S. Svelle, J. Catal. 2017, 351, 33-48.

[29] Q. Liu, D. Wen, Y. Yang, Z. Fei, Z. Zhang, X. Chen, J. Tang, M. Cui, X. Qiao, Appl. Surf. Sci. 2018, 435, 945-952.

[30] B. T. W. Lo, L. Ye, C. A. Murray, C. C. Tang, D. Mei, S. C. E. Tsang, J. Catal. 2018, 365, 145-152.

[31] W. Dai, C. Wang, M. Dyballa, G. Wu, N. Guan, L. Li, Z. Xie, M. Hunger, ACS Catal. 2015, 5, 317-326.

[32] P. N. Plessow, F. Studt, ACS Catal. 2017, 7, 7987-7994.

[33] T. R. Forester, R. F. Howe, J. Am. Chem. Soc. 1987, 109, 5076-5082.

[34] J. S. Martinez-Espin, M. Mortén, T. V. W. Janssens, S. Svelle, P. Beato, U. Olsbye, Catal. Sci. Technol. 2017, 7, 2700-2716.

[35] J. S. Martínez-Espín, K. De Wispelaere, T. V. W. Janssens, S. Svelle, K. P. Lillerud, P. Beato, V. Van Speybroeck, U. Olsbye, ACS Catal. 2017, 7, 5773-5780

[36] J. S. Martinez-Espin, K. De Wispelaere, M. Westgård Erichsen, S. Svelle, T. V. W. Janssens, V. Van Speybroeck, P. Beato, U. Olsbye, J. Catal. 2017, 349, 136-148

[37] Y. Li, M. Zhang, D. Wang, F. Wei, Y. Wang, J. Catal. 2014, 311, 281-287.

[38] P. Pérez-Uriarte, A. Ateka, A. T. Aguayo, A. G. Gayubo, J. Bilbao, Chem. Eng. J. 2016, 302, 801-810.

[39] P. Pérez-Uriarte, A. Ateka, A. G. Gayubo, T. Cordero-Lanzac, A. T. Aguayo, J. Bilbao, Chem. Eng. J. 2017, DOI 10.1016/j.cej.2016.11.104.

[40] T. Xu, Q. Zhang, H. Song, Y. Wang, J. Catal. 2012, 295, 232-241.

[41] S. Svelle, S. Aravinthan, M. Bjørgen, K. P. Lillerud, S. Kolboe, I. M. Dahl, U. Olsbye, J. Catal. 2006, 241, 243-254.

[42] U. Olsbye, O. V. Saure, N. B. Muddada, S. Bordiga, C. Lamberti, M. H. Nilsen, K. P. Lillerud, S. Svelle, Catal. Today 2011, 171, 211-220.

[43] M. Ibáñez, M. Gamero, J. Ruiz-Martínez, B. M. M. Weckhuysen, A. T. T. Aguayo, J. Bilbao, P. Castaño, Catal. Sci. Technol. 2016, 6, 296-306. 
[44] F. Schüth, M. D. Ward, J. M. Buriak, Chem. Mater. 2018, 30, 3599-3600. [45] S. L. Scott, ACS Catal. 2018, 8, 8597-8599.

[46] M. H. Nilsen, S. Svelle, S. Aravinthan, U. Olsbye, Appl. Catal. A Gen. 2009, 367, 23-31.

[47] S. M. Campbell, D. M. Bibby, J. M. Coddington, R. F. Howe, J. Catal. 1996, 161, 350-358.

[48] A. G. Gayubo, A. T. Aguayo, A. L. Morán, M. Olazar, J. Bilbao, AlChE J. 2002, 48, 1561-1571.

[49] F. L. Bleken, T. V. W. Janssens, S. Svelle, U. Olsbye, Microporous Mesoporous Mater. 2012, 164, 190-198.

[50] A. G. Marshall, R. P. Rodgers, Acc. Chem. Res. 2004, 37, 53-59.

[51] M. Gamero, B. Valle, A. G. Gayubo, P. Castaño, A. T. Aguayo, J. Bilbao, Ind. Eng. Chem. Res. 2018, 57, 908-919.

[52] C. Wang, J. Xu, G. Qi, Y. Gong, W. Wang, P. Gao, Q. Wang, N. Feng, X. Liu, F. Deng, J. Catal. 2015, 332, DOI 10.1016/j.jcat.2015.10.001.

[53] E. Borodina, H. Sharbini Harun Kamaluddin, F. Meirer, M. Mokhtar, A. M. Asiri, S. A. Al-Thabaiti, S. N. Basahel, J. Ruiz-Martinez, B. M. Weckhuysen, ACS Catal. 2017, 7, 5268-5281.

[54] J. Goetze, F. Meirer, I. Yarulina, J. Gascon, F. Kapteijn, J. Ruiz-Martínez, B. M. Weckhuysen, ACS Catal. 2017, 7, 4033-4046.

[55] I. Yarulina, S. Bailleul, A. Pustovarenko, J. Ruiz-Martinez, K. De Wispelaere, J. Hajek, B. M. Weckhuysen, H. Klaartje, Marc Baldus, V. Van Speybroeck, et al., ChemCatChem 2016, 8, 3057-3063.

[56] M. Ibáñez, E. Epelde, A. T. A. T. Aguayo, A. G. A. G. A. G. Gayubo, J. Bilbao, P. Castaño, Appl. Catal. A Gen. 2017, 543, 1-9.

[57] R. Khare, Z. Liu, Y. Han, A. Bhan, J. Catal. 2017, 348, 300-305.

[58] A. Ochoa, B. Aramburu, B. Valle, D. E. Resasco, J. Bilbao, A. G. Gayubo, P. Castaño, Green Chem. 2017, 19, 4315-4333.

[59] P. Castaño, A. Gutiérrez, I. Hita, J. M. Arandes, A. T. Aguayo, J. Bilbao, Energy and Fuels 2012, 26, 1509-1519.

[60] T. Cordero-Lanzac, I. Hita, A. Veloso, J. M. Arandes, J. RodríguezMirasol, J. Bilbao, T. Cordero, P. Castaño, Chem. Eng. J. 2017, 327, DOI 10.1016/j.cej.2017.06.077.

[61] E. Epelde, J. I. Santos, P. Florian, A. T. Aguayo, A. G. Gayubo, J. Bilbao, P. Castaño, Appl. Catal. A Gen. 2015, 505, 105-115.

[62] Z. Wan, G. K. Li, C. Wang, H. Yang, D. Zhang, Appl. Catal. A Gen. 2018 , $549,141-151$.

[63] T. Fu, R. Qi, W. Wan, J. Shao, J. Z. Wen, Z. Li, ChemCatChem 2017, 9 , 4212-4224.

[64] C. Bai, L. Liu, H. Sun, J. Phys. Chem. C 2012, 116, 7029-7039.

[65] D. Lesthaeghe, V. Van Speybroeck, G. B. Marin, M. Waroquier, Ind. Eng. Chem. Res. 2007, 46, 8832-8838.
[66] P. E. Sinclair, C. Richard A. Catlow, J. Chem. Soc. Faraday Trans. 1997, 93, 333-345.

[67] S. R. Blaszkowski, R. A. Van Santen, J. Am. Chem. Soc. 1996, 118, 5152-5153.

[68] D. Lesthaeghe, V. Van Speybroeck, G. B. Marin, M. Waroquier, Angew. Chemie - Int. Ed. 2006, 45, 1714-1719.

[69] E. Spanó, G. Tabacchi, A. Gamba, E. Fois, J. Phys. Chem. B 2006, 110, 21651-21661.

[70] D. Lesthaeghe, V. Van Speybroeck, G. B. Marin, M. Waroquier, Chem. Phys. Lett. 2006, 417, 309-315.

[71] R. Shah, M. C. Payne, M.-H. Lee, J. D. Gale, Science (80-. ). 1996, 271, 1395-1397.

[72] H. Schulz, Catal. Today 2010, 154, 183-194.

[73] M. W. Erichsen, M. Mortén, S. Svelle, O. Sekiguchi, E. Uggerud, U. Olsbye, ChemCatChem 2015, 7, 4143-4147.

[74] D. Lesthaeghe, J. VanderMynsbrugge, M. Vandichel, M. Waroquier, V. VanSpeybroeck, ChemCatChem 2011, 3, 208-212.

[75] A. G. Gayubo, A. T. Aguayo, A. Atutxa, R. Aguado, M. Olazar, J. Bilbao, Ind. Eng. Chem. Res. 2004, 43, 2619-2626.

[76] C. M. Wang, Y. D. Wang, Z. K. Xie, Z. P. Liu, J. Phys. Chem. C 2009, 113, 4584-4591.

[77] K. De Wispelaere, C. S. Wondergem, B. Ensing, K. Hemelsoet, E. J. Meijer, B. M. Weckhuysen, V. Van Speybroeck, J. Ruiz-Martínez, ACS Catal. 2016, 6, 1991-2002.

[78] A. T. Aguayo, P. Castaño, D. Mier, A. G. Gayubo, M. Olazar, J. Bilbao, Ind. Eng. Chem. Res. 2011, 50, DOI 10.1021/ie200946n.

[79] P. Castaño, J. Ruiz-Martínez, E. Epelde, A. G. A. G. Gayubo, B. M. B. M. Weckhuysen, Chem CatChem 2013, 5, 2827-2831.

[80] P. Pérez-Uriarte, M. Gamero, A. Ateka, M. Díaz, A. T. Aguayo, J. Bilbao, Ind. Eng. Chem. Res. 2016, 55, 1513-1521.

[81] C. Vogt, B. M. Weckhuysen, J. Ruiz-Martínez, ChemCatChem 2017, 9 , 183-194.

[82] T. P. Senftle, S. Hong, M. M. Islam, S. B. Kylasa, Y. Zheng, Y. K. Shin, C Junkermeier, R. Engel-Herbert, M. J. Janik, H. M. Aktulga, et al., NPJ Comput. Mater. 2016, 2, 15011.

[83] J. D. Gale, A. L. Rohl, Mol. Simul. 2003, 29, 291-341.

[84] S. A. Trygubenko, D. J. Wales, J. Chem. Phys. 2004, 120, 2082-2094. [85] C. W. Kim, N. H. Heo, K. Seff, J. Phys. Chem. C 2011, 115, 24823-24838.

[86] A. Ghorbanpour, J. D. Rimer, L. C. Grabow, Catal. Commun. 2014, 52, 98-102. 
Table of Contents

\section{FULL PAPER}

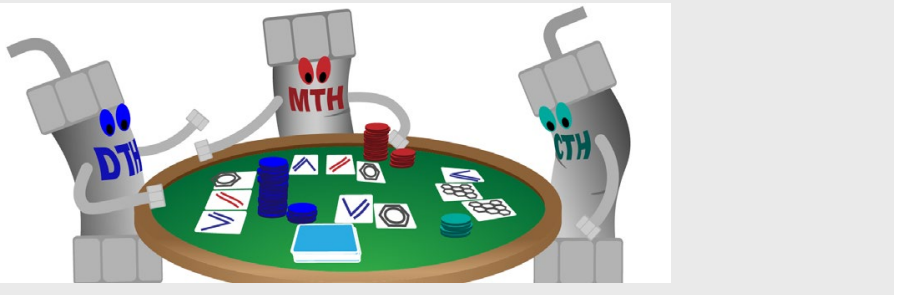

J. Valecillos, H. Manzano, A.T. Aguayo,

J. Bilbao, P. Castaño*

Page No. - Page No.

Kinetic and deactivation differences among methanol, dimethyl ether and chloromethane as stock for hydrocarbons

Who will win this bet? Methanol, dimethyl ether and chloromethane are disputing who is best to produce hydrocarbons. Methanol and dimethyl ether are quicker and can hold bets for longer. Chloromethane has an ace: higher yields of olefins and much greater proportion of propylene. The table is a H-ZSM- 5 zeolite catalyst. The game is open. 